\title{
Regional non-uniformity of wall dynamics in normal left ventricle ${ }^{\star}$
}

\author{
E SHAPIRO, D L MARIER, M G ST JOHN SUTTON, D G GIBSON \\ From the Cardiac Department, Brompton Hospital, London
}

SUMMARY M-mode echocardiograms were performed in 31 normal children in order to compare myocardial wall dynamics in different regions of the left ventricle. Tracings were recorded at the level of the mitral valve ring (level 1), near the tips of the mitral valve leaflets (level 2), and in the region of the papillary muscles (level 3 ) and were digitised. Fractional shortening increased from 31.7 per cent at level 1 to 36.5 per cent at level 3. Peak VCF and minor dimension lengthening rate were the same at all three levels, as were end-diastolic posterior wall thickness and peak systolic wall thickening rate. Striking regional differences, however, were seen in the extent of systolic posterior wall thickening which increased from 55 per cent at the base to 106 per cent at the papillary muscles, and in peak posterior wall thinning rate, which increased from $6.4 \mathrm{~cm} / \mathrm{s}$ at the base to $10.0 \mathrm{~cm} / \mathrm{s}$ at the papillary muscles. There was greater systolic inward movement of epicardium at level 1 than at levels 2 and 3 . The septum thinned and thickened more slowly than did the posterior wall and did not show major differences between levels. Systolic reduction in minor dimension thus occurs largely by thickening of the wall at level 3 and by sphincter-like inward movement of the entire wall at level 1 . These regional differences can be explained by a circumferential arrangement of myocardial fibres at the base of the heart and a more prominent longitudinal component towards the apex. Thus, non-uniformity of function is a prominent feature of the normal left ventricle and may reflect regional variation in its structure.

Echocardiographers have long recognised that regional differences may exist in wall dynamics and dimensions in the normal left ventricle, and have established standard positions at which measurements of ventricular performance are to be made. ${ }^{1}$ These variations, however, have not been systematically investigated. Indeed, they are often ignored and the left ventricle assumed to be a simple pump with uniformity of structure and function. ${ }^{2}$ The present study was undertaken to examine these differences in greater detail and to determine the extent to which they reflect the complex architecture of the heart and contribute to efficient ventricular function.

\section{Methods}

Observations were made in 31 normal children, aged 3 to 12 years. None had clinical evidence of cardiovascular disease. M-mode echocardio-

*Supported by grants from the British Heart Foundation and the Burroughs Wellcome Foundation.

Received for publication 29 July 1980 grams were recorded at three levels in the ventricle, located by their relation to the mitral valve. In each subject, either Cambridge Instruments $\mathrm{M}$-mode equipment was used directly, or an ATL sector scanner was first used to find each level in the minor axis view. M-mode recordings were then made.

(1) At the level of the mitral valve cusps. This was the highest level in the ventricle at which posterior wall echoes could be continuously recorded. At this level, the echo from the anterior cusp was recorded throughout the cardiac cycle, and posterior to it was the posterior cusp or the ventricular myocardium which thickened during systole (Fig. 1a). This position was also confirmed using the two dimensional display, recorded in the minor axis projection (Fig. 1b).

(2) At the level of the tips of the cusps, lower in the cavity. Here, both cusps were visible at the onset of diastolic separation, but not during the remainder of ventricular filling (Fig. $2 a, b$ ).

(3) At the level of the papillary muscles, which were demonstrable anterior to the endocardium of the posterior wall on the M-mode (Fig. $3 \mathrm{a}$ ) and as 
characteristic discrete echoes within the left ventricular cavity on the two dimensional image (Fig. 3b).

Echocardiograms were recorded with a Cambridge Instruments fibreoptic recorder, at a paper speed of $100 \mathrm{~mm} / \mathrm{s}$, along with a simultaneous electrocardiogram and high frequency phonocardiogram. Echoes from the endo- and epicardial surfaces of the posterior wall and the right and left sides of the septum were digitised. ${ }^{3}$ From the computer output, the following measurements were made:

(1) Left ventricular cavity size: end-diastolic and end-systolic dimensions (taken as those synchronous

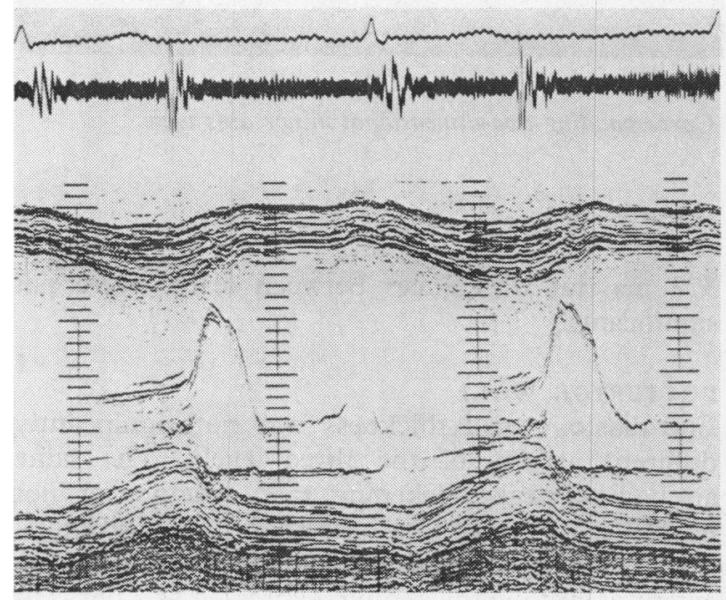

(a) with the $\mathrm{Q}$ wave of the electrocardiogram, and A2 on the phonocardiogram, respectively) were measured and fractional shortening derived. Peak velocities of dimensional shortening were estimated from the trace of normalised velocity during systole (peak VCF) and diastole, expressed with the units $\mathrm{s}^{-1}$. The time from the $\mathrm{Q}$ wave of the electrocardiogram to minimum left ventricular dimension was measured.

(2) Posterior wall: end-diastolic and peak wall thickness, per cent thickening, and peak thickening and thinning rates in $\mathrm{cm} / \mathrm{s}$ were measured. The time from the $Q$ wave of the electrocardiogram to peak wall thickness was recorded. To clarify the

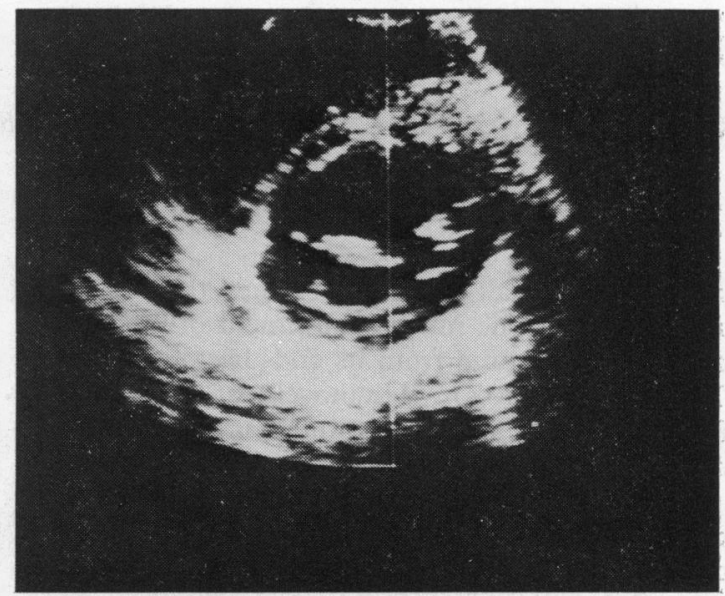

(b)

Fig. 1 (a) Normal M-mode echocardiogram at level 1, with simultaneous phono- and electrocardiogram.

(b) Corresponding left parasternal minor axis cross sectional view of the left ventricle.

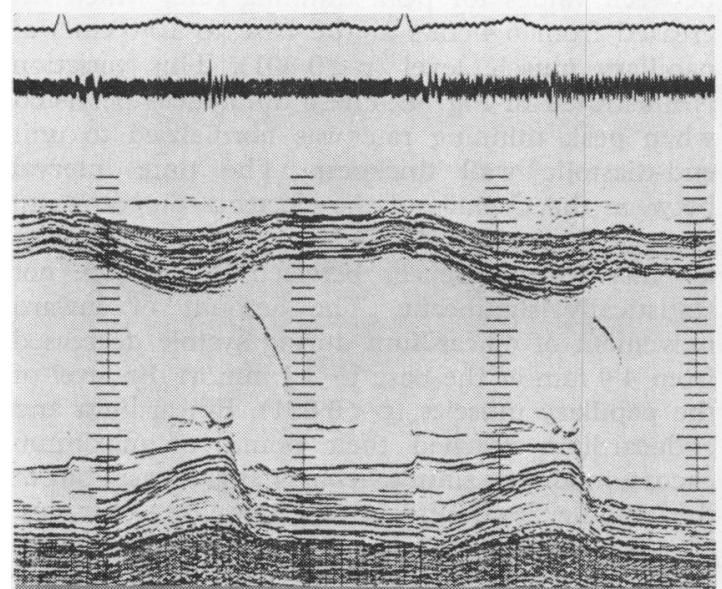

(a)

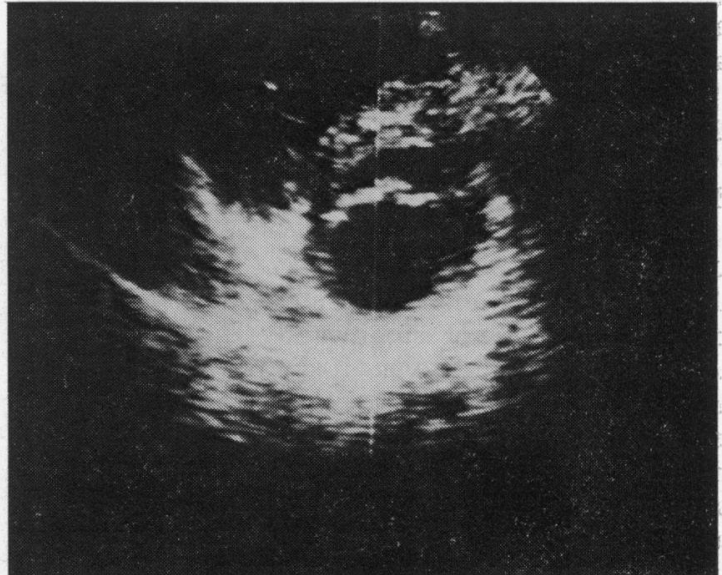

(b)

Fig. 2 (a) Normal M-mode echocardiogram at level 2. (b) Corresponding two-dimensional minor axis view. 


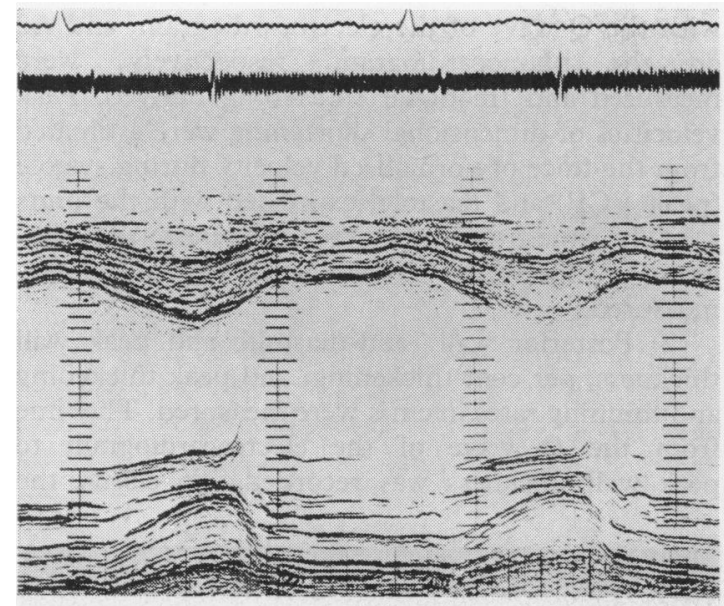

(a)

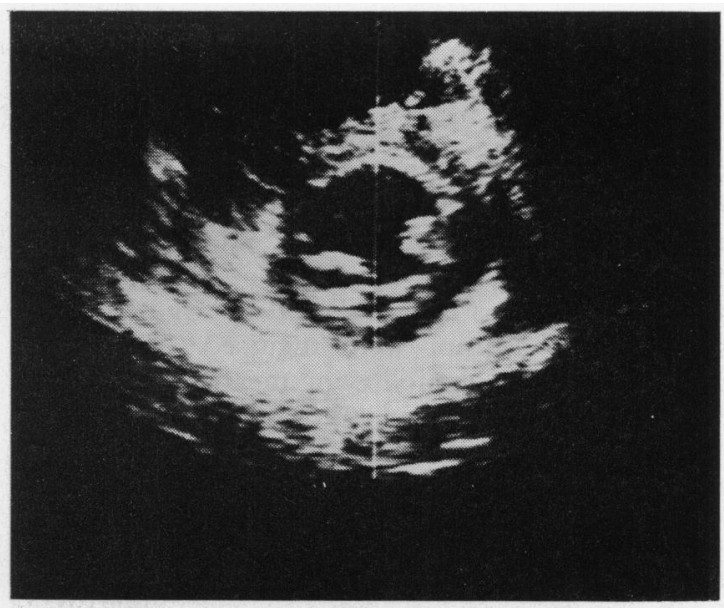

(b)

Fig. 3 (a) Normal M-mode echocardiogram at level 3. (b) Corresponding two-dimensional minor axis view.

mechanism of wall thickening further, the maximum amount of systolic inward movement of the epicardium was measured from its end-diastolic position. The timing of peak inward movement was identified for both endo- and epicardium, and the time interval between the two was derived.

(3) Septum: end-diastolic and end-systolic thickness, per cent thickening, peak thickening and thinning rates, and the time to peak thickness from the $Q$ wave of the electrocardiogram were measured, as for the posterior wall.

Corresponding values of these variables were compared at the three levels of the cavity. Statistical significance of differences between mean values was assessed by analyses of variance and $t$ tests as appropriate.

\section{Results}

These are given in detail in the Table.

\section{CAVITY DIMENSIONS}

At end-diastole and end-systole, left ventricular cavity size was not significantly different at the three levels. There was a slight but significant increase in fractional shortening from 32 per cent at the base to 37 per cent at the level of the papillary muscles $(p<0.001)$. Peak normalised rate of shortening of the transverse dimension (peak VCF) and peak lengthening rate were unchanged from the base to the level of the papillary muscles. The time from the $Q$ wave of the electrocardiogram to minimum left ventricular dimension ranged from 360 to
$378 \mathrm{~ms}$ but differences between levels were not significant.

POSTERIOR WALL

End-diastolic wall thickness was not significantly different at any of the three levels. The same applied to peak thickening rate, whether or not normalised to unit end-diastolic wall thickness. There was, however, a progressive increase in the extent of systolic thickening, expressed as a per cent increase in thickness, from 55 per cent at level 1 to 77 per cent at level 2 and 106 per cent at level 3 $(p<0.001)$. There were also major differences between values for peak thinning rate, which increased from $6.4 \mathrm{~cm} / \mathrm{s}$ at the base to $10.0 \mathrm{~cm} / \mathrm{s}$ at papillary muscle level $(p<0.001)$. This variation is illustrated in Fig. 4. These differences persisted when peak thinning rate was normalised to unit end-diastolic wall thickness. The time interval between the $Q$ wave of the electrocardiogram and peak posterior wall thickness varied from 389 to $400 \mathrm{~ms}$, but differences between levels were not statistically significant. The amount of inward movement of epicardium during systole decreased from $4.9 \mathrm{~mm}$ at the base to $3.1 \mathrm{~mm}$ at the level of the papillary muscles $(p<0.001)$. Epicardium and endocardium reached their points of maximum excursion almost simultaneously at the base, but at the middle level and at the papillary muscles, epicardium peaked first, with the peak of endocardial movement coming 18 and $20 \mathrm{msec}$ later $(p<0.001)$, respectively. Wall thickening thus continued after aortic closure (as determined from 
Table Comparisons of cavity dimensions and wall dynamics between levels

\begin{tabular}{|c|c|c|c|c|c|c|c|}
\hline & $\begin{array}{l}\text { Level } 1 \\
(\text { mean } \pm 1 S D)\end{array}$ & $\begin{array}{l}\text { Significance of } \\
\text { differences } \\
\text { between levels } \\
1 \text { and } 2\end{array}$ & $\begin{array}{l}\text { Level } 2 \\
(\text { mean } \pm 1 S D)\end{array}$ & $\begin{array}{l}\text { Significance of } \\
\text { differences } \\
\text { between levels } \\
2 \text { and } 3\end{array}$ & $\begin{array}{l}\text { Level } 3 \\
(\text { mean } \pm 1 S D)\end{array}$ & $\begin{array}{l}\text { Significance of } \\
\text { difference } \\
\text { between levels } \\
1 \text { and } 3\end{array}$ & $\begin{array}{l}\text { Overall } \\
\text { significance of } \\
\text { differences } \\
\text { between all } \\
\text { levels by } \\
\text { analysis of } \\
\text { variance }\end{array}$ \\
\hline $\begin{array}{l}\text { End-diastolic dimension }(\mathrm{cm}) \\
\text { End-systolic dimension }(\mathrm{cm}) \\
\text { Fractional shortening }(\%) \\
\text { Peak normalised rate of minor }\end{array}$ & $\begin{array}{l}3 \cdot 8 \pm 0 \cdot 45 \\
2 \cdot 6 \pm 0 \cdot 37 \\
32 \pm 6\end{array}$ & $\begin{array}{l}\text { NS } \\
\text { NS } \\
\mathrm{p}<0.05\end{array}$ & $\begin{array}{l}3 \cdot 9 \pm 0 \cdot 40 \\
2 \cdot 5 \pm 0 \cdot 32 \\
35 \pm 4\end{array}$ & $\begin{array}{l}\text { NS } \\
\text { NS } \\
\text { NS }\end{array}$ & $\begin{array}{l}3 \cdot 9 \pm 0 \cdot 45 \\
2 \cdot 5 \pm 0 \cdot 31 \\
37 \pm 5\end{array}$ & $\begin{array}{l}\text { NS } \\
\text { NS } \\
\mathrm{p}<0.001\end{array}$ & $\begin{array}{l}\text { NS } \\
\text { NS } \\
\mathrm{p}<0.01\end{array}$ \\
\hline $\begin{array}{l}\text { dimension increase }\left(\mathrm{s}^{-1}\right) \\
\text { Peak normalised rate of minor } \\
\text { dimension shortening (peak }\end{array}$ & $3 \cdot 3 \pm 1$ & NS & $3.9 \pm 2$ & NS & $3 \cdot 9 \pm 1$ & NS & NS \\
\hline $\begin{array}{l}\text { VCF) }\left(\mathrm{s}^{-1}\right) \\
\text { End-diastolic posterior wall }\end{array}$ & $3.9 \pm 5$ & NS & $3 \cdot 5 \pm 1$ & NS & $3 \cdot 8 \pm 2$ & NS & NS \\
\hline $\begin{array}{l}\text { thickness (cm) } \\
\text { End-systolic posterior wall }\end{array}$ & $0.64 \pm 0.2$ & NS & $0.64 \pm 0.2$ & NS & $0.58 \pm 0.2$ & NS & NS \\
\hline $\begin{array}{l}\text { thickness }(\mathrm{cm}) \\
\text { Percentage systolic thickening }\end{array}$ & $0.99 \pm 0.2$ & NS & $1 \cdot 1 \pm 02$ & NS & $1 \cdot 1 \pm 0 \cdot 2$ & $\mathrm{p}<0.02$ & $\mathrm{p}<0.05$ \\
\hline $\begin{array}{l}\text { of posterior wall }(\%) \\
\text { Peak rate of posterior wall }\end{array}$ & $55 \pm 27$ & $\mathrm{p}<0.02$ & $77 \pm 37$ & $\mathrm{p}<0.02$ & $106 \pm 51$ & $\mathrm{p}<0.001$ & $\mathrm{p}<0.001$ \\
\hline $\begin{array}{l}\text { thickening }(\mathrm{cm} / \mathrm{s}) \\
\text { Peak rate of posterior wall }\end{array}$ & $3.5 \pm 1$ & NS & $3 \cdot 6 \pm 1$ & NS & $3 \cdot 6 \pm 0.8$ & NS & NS \\
\hline & $6 \cdot 4 \pm 3$ & $\mathrm{p}<0.001$ & $9 \cdot 0 \pm 3$ & $\mathrm{p}<0.20$ & $10 \cdot 0 \pm 3$ & $\mathrm{p}<0.001$ & $\mathrm{p}<0.001$ \\
\hline $\begin{array}{l}(\mathrm{cm}) \\
\text { End-systolic septal thickness }\end{array}$ & $0.63 \pm 0.15$ & NS & $0 \cdot 67 \pm 0 \cdot 10$ & NS & $0.61 \pm 0.13$ & NS & NS \\
\hline $\begin{array}{l}(\mathrm{cm}) \\
\text { Percentage systolic thickening } \\
\text { of septum }(\%) \\
\text { Peak rate of septal thickening }\end{array}$ & $\begin{array}{r}0.97 \pm 0 \cdot 1 \\
34 \pm 13\end{array}$ & $p<0.05$ & $\begin{array}{l}1 \cdot 1 \pm 0 \cdot 2 \\
63 \pm 31\end{array}$ & NS & $\begin{array}{l}1 \cdot 1 \pm 0 \cdot 2 \\
66 \pm 25\end{array}$ & $p<0.05$ & $\mathrm{p}<0.05$ \\
\hline $\begin{array}{l}(\mathrm{cm} / \mathrm{s}) \\
\text { Peak rate of septal thinning }(\mathrm{cm} / \mathrm{s}) \\
\text { Time interval from start of } \\
Q \text { wave to minimum minor }\end{array}$ & $\begin{array}{l}2 \cdot 8 \pm 0 \cdot 8 \\
4 \cdot 2 \pm 1\end{array}$ & $\begin{array}{l}\text { NS } \\
\text { NS }\end{array}$ & $\begin{array}{l}3 \cdot 1 \pm 1 \\
4 \cdot 0 \pm 2\end{array}$ & $\begin{array}{l}\text { NS } \\
\text { NS }\end{array}$ & $\begin{array}{l}2 \cdot 7 \pm 0 \cdot 7 \\
3 \cdot 2 \pm 1\end{array}$ & $\begin{array}{l}\text { NS } \\
\mathrm{p}<0.05\end{array}$ & $\begin{array}{l}\text { NS } \\
\text { NS }\end{array}$ \\
\hline $\begin{array}{l}\text { axis dimension (ms) } \\
\text { Time interval from start of } Q \\
\text { wave to peak posterior wall }\end{array}$ & $378 \pm 51$ & NS & $367 \pm 32$ & NS & $360 \pm 31$ & NS & NS \\
\hline $\begin{array}{l}\text { thickness (ms) } \\
\text { Time interval from start of } Q \\
\text { wave to peak septal thickness }\end{array}$ & $389 \pm 59$ & NS & $396 \pm 31$ & NS & $400 \pm 26$ & NS & NS \\
\hline $\begin{array}{l}\text { (ms) } \\
\text { Systolic inward movement of }\end{array}$ & $403 \pm 85$ & NS & $376 \pm 72$ & NS & $363 \pm 58$ & NS & NS \\
\hline $\begin{array}{l}\text { epicardium (mm) } \\
\text { Interval between peak of } \\
\text { epicardial excursion and peak } \\
\text { of endocardial excursion (ms) }\end{array}$ & $4 \cdot 9 \pm 1 \cdot 8$ & $\mathrm{p}<0.001$ & $3.7 \pm 1.8$ & NS & $3 \cdot 1 \pm 1 \cdot 5$ & $\mathrm{p}<0.001$ & $\mathrm{p}<0.001$ \\
\hline
\end{tabular}

simultaneous phonocardiogram) but was complete before mitral valve opening at all levels.

\section{SEPTUM}

End-diastolic and end-systolic septal thickness showed no consistent differences with level in the cavity, nor did values differ significantly from those from the posterior wall. Septal dynamics, however, showed a number of distinctive features. Peak thickening rates were not different from peak thinning rates, but both were significantly less than those of the posterior wall. The septal thickening rate did not show variation with position in cavity. Peak thinning rate decreased slightly from $4.2 \mathrm{~cm} / \mathrm{s}$ at the base, to $4.0 \mathrm{~cm} / \mathrm{s}$ at the middle level, to $3.2 \mathrm{~cm} / \mathrm{s}$ at the level of the papillary muscles, the change from level 1 to level 3 showing borderline statistical significance $(p<0.05)$. This slight variation is in the

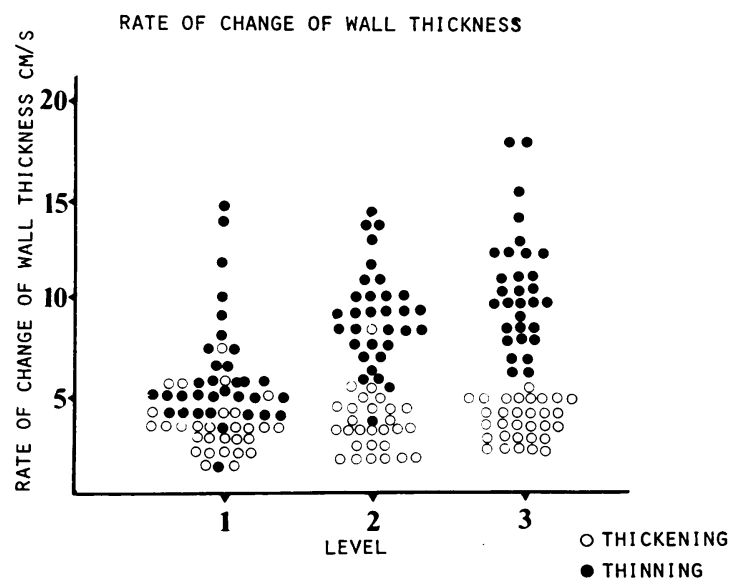

Fig. 4 Regional variation in the peak rates of change of thickness. 
opposite direction from that seen in the posterior wall.

\section{Discussion}

It is widely assumed that the normal pattern of left ventricular wall movement is uniform and that any departure from this is to be taken as evidence of disease. In the present study, however, we have shown that in a group of normal children, consistent differences can be shown in the extent and velocity of wall thickening and thinning which are dependent on position within the ventricle. On the basis of left ventricular angiograms, minor regional differences have previously been described in the overall amplitude of movement, its peak velocity, and changes in position during isovolumic relaxation. ${ }^{4-6}$ Angiography, however, is an unsuitable method for their demonstration because truly normal subjects are rarely studied, and because it fails to define endocardium adequately during late systole and early relaxation. ${ }^{7}$ Furthermore, regional endocardial movement must be analysed with respect to an arbitrary reference point used to align successive cine frames, and so may not be distinguishable from overall displacement of the heart in space. Though the necessity for this reference point can be eliminated by studying local changes in wall thickness, angiography is particularly unsuited for this because of the poor definition of epicardium and the relatively low frame rate. The use of $\mathrm{M}$-mode echocardiography avoids these problems. Regional function can be investigated by determining position in the ventricle with a 2-D image or simply by using the mitral valve as a landmark. Both methods were used in the present study.

If myocardial structure were uniform, then for a given decrease in cavity volume, the extent of regional thickening would depend only on enddiastolic volume and wall thickness. In the present study, end-diastolic posterior wall and septal thicknesses at three levels were not significantly different. Therefore, wall dynamics, including extent of thickening and peak rates of thickening and thinning should also have been identical. The observed values, however, differed widely from this prediction. Unlike the peak rate of posterior wall thickening, which was the same at all three levels, the extent of posterior wall thickening, and in particular, peak thinning rate, were both less at level 1, the base of the cavity, and increased toward the papillary muscles (Fig. 4). These variations could not have been the result of differences in the angle of the beam at the three levels, since they persisted after normalisation to unit end-diastolic wall thickness. Therefore the mech- anism of minor axis dimension change differed throughout the ventricle. At the level of the papillary muscles, reduction in transverse axis was due almost entirely to wall thickening, while at the base, reduced wall thickening was partly compensated for by inward movement of epicardium in a sphincter-like manner.

Further discrepancies were apparent when septal motion was considered. Though its end-diastolic thickness was no different from that of the posterior wall, its thickening rate was significantly less. Peak normalised rate of wall thickening has been suggested as a measure of local myocardial performance, ${ }^{8}$ but there seems no reason to believe that such impairment is a feature of the normal septum. Further, unlike the posterior wall, the rate of septal thickening was not different from that of thinning. Therefore, the phenomenon of rapid thinning shown by the posterior wall, previously shown to be independent of left ventricular filling ${ }^{9}$ and so likely to be an intrinsic property of the wall itself, is not an invariable property of relaxing myocardium. Finally, the striking increases in extent of thickening and rate of thinning toward the papillary muscles seen in the posterior wall were not present in the septum. In fact, there was a small but significant tendency for the reverse to occur, with the extent of septal thickening and peak rate of thinning to be greater at the base than at the papillary muscles. It is clear, therefore, that systematic and complex variation in local function can be detected in the normal left ventricle.

The mechanism of left ventricular dimension changes has been explored by a number of authors. Sallin $^{10}$ pointed out that the normal reduction in minor axis is much too great to be explained solely on the basis of shortening of the sarcomeres of circumferentially oriented fibres and therefore that an additional effect of thickening of longitudinally arranged fibres must be contributing. These ideas have recently been developed by Dumesnil et al., ${ }^{11}$ who derived ventricular long axis shortening from measurements of minor dimension shortening and posterior wall thickening by echocardiography, and found good correlation with angiographic measurements. Regional variation in thickening and rate of thinning may thus be the result of differences in orientation of myocardial fibres, avoiding the necessity to invoke local changes in the properties of the fibres themselves.

This explanation of our observations gives rise to a series of predictions concerning the nature of left ventricular fibre architecture which can be compared to anatomical findings. Those regions of the ventricle where the most thickening and the most rapid thinning are seen, near the papillary muscles, 
should be the regions where the contribution of longitudinally directed fibres is greatest. In contrast, the sphincter-like pattern of motion at level 1 would indicate a more circumferential pattern of arrangement of fibres at the base. Regional differences in fibre arrangement in the left ventricle have been shown in a number of previous anatomical studies. A basal circumferential ring of muscle was originally described by Winslow in $1711,{ }^{12}$ and repeatedly confirmed by dissection since then. ${ }^{13}{ }^{14}$ Because possible limitations of dissection as a means of studying left ventricular anatomy have been pointed out by Grant, ${ }^{15}$ this question has recently been restudied using morphometric techniques. ${ }^{16}$ This has confirmed the presence of the predominantly circumferential arrangement of fibres at the base in contrast to continuously changing fibre angle across the wall at the level of the papillary muscles. The septum is composed largely of circumferential fibres. Regional differences in wall dynamics thus seem to be explicable on the basis of local fibre structure, a mechanism that seems preferable to the alternative, that the myocardium has different properties of contraction and relaxation in different parts of the ventricle.

It has previously been shown that an increase in posterior wall thickness normally occurs during the time interval between aortic valve closure and mitral valve opening. ${ }^{9}$ This study confirms that finding, and also discloses a dissociation of changes in wall thickness from those of epicardial movement. At levels 2 and 3, during this period, the epicardium has already begun to move outward though the endocardium continues to move inward. Thus for a brief period, averaging $20 \mathrm{~ms}$ in duration, thickening of the wall is accomplished by movement of its two surfaces in opposite directions, a thickening that must be the result of shortening of longitudinally oriented fibres. Indeed it seems that contraction of these longitudinal fibres was delayed or prolonged compared with that of circumferentially arranged ones. There was no evidence of sudden posterior motion of the whole heart at this stage of the cardiac cycle in the movement of other structures, which might have explained this unexpected finding. An alternative mechanism, that this thickening during isovolumic relaxation is solely the result of early diastolic coronary flow with engorgement of the wall, appears unlikely because the posterior wall at level 1 and the septum show no such changes. Anatomical studies have shown that in the posterior wall at positions corresponding to levels 2 and 3, longitudinally arranged fibres are predominantly subendocardial. ${ }^{13} 16$ Though there is no direct evidence of this in man, delay in the contraction of the papillary muscles with respect to that of the epicardium has been shown in the dog. ${ }^{17} 18$ Initiation of contraction in the epicardium and subsequent contraction of the remainder of myocardium and the papillary muscles is compatible with our observations. Subendocardial ischaemia might thus be expected to produce a characteristic disturbance of regional function consisting of reduced wall thickening, impaired thinning rate, increased epicardial motion, and loss of normal wall thickening during isovolumic relaxation.

From a more practical point of view, our results clearly indicate that the behaviour of the posterior wall in the standard position for making $\mathrm{M}$-mode echocardiographic measurements is not typical of that of the myocardium as a whole. Estimations of wall thickness based on observations of cavity volume and the assumption of constant myocardial mass are also subject to this limitation. These findings also stress that regional variation must clearly be taken into account in interpreting apparent abnormalities of left ventricular wall motion in patients with myocardial disease. Specific disease processes such as coronary artery disease, left ventricular hypertrophy, and the cardiomyopathies might be further studied with a view to elucidating the relation between distortion of myocardial fibre architecture and overall left ventricular dysfunction.

\section{References}

1 Popp RL, Filly K, Brown OR, Harrison DC. Effect of transducer placement on echocardiographic measurements of left ventricular dimensions. Am $\mathcal{F}$ Cardiol 1975; 35: 537-40.

2 Braunwald E, Ross J Jr, Sonnenblick EH. Mechanisms of contraction of the normal and failing heart. $N$ Engl f Med 1967; 277: 1012-22.

3 Gibson DG, Brown DJ. Measurement of instantaneous left ventricular dimension and filling rate in man, using echocardiography. Br Heart $\mathcal{f}$ 1973; 35: 1141-9.

4 Ingels NB Jr, Daughters GT II, Stinson EB, Alderman EL. Is wall motion in the normal left ventricle uniform, symmetric and synergic? Circulation 1979; 59-60, suppl: II-93.

5 Gibson DG, Sanderson JE, Traill TA, Brown DJ, Goodwin JF. Regional left ventricular wall movement in hypertrophic cardiomyopathy. Br Heart $\mathcal{f}$ 1978; 40: 1327-33.

6 Gibson DG, Prewitt TA, Brown DJ. Analysis of left ventricular wall movement during isovolumic relaxation and its relation to coronary artery disease. Br Heart f 1976; 38: 1010-9.

7 Hugenholtz PG, Kaplan E, Hull E. Detection of left ventricular wall thickness by angiocardiography. Am Heart f 1969; 78: 513-22. 
8 Dumesnil JG, Ritman EL, Frye RL, Gau GT, Rutherford BD, Davis GD. Quantitative determination of regional left ventricular wall dynamics by Roentgen videometry. Circulation 1974; 50: 700-8.

9 Traill TA, Gibson DG, Brown DJ. Study of left ventricular wall thickness and dimension changes using echocardiography. Br Heart f 1978; 40: 162-9.

10 Sallin EA. Fiber orientation and ejection fraction in the human left ventricle. Biophys $\mathcal{f}$ 1969; 9: 954-64.

11 Dumesnil JG, Shoucri RM, Laurenceau J-L, Turcot J. A mathematical model of the dynamic geometry of the intact left ventricle and its application to clinical data. Circulation 1979; 59: 1024-34.

12 Winslow JB. Observations sur les fibres du coeur et sur ses valvules. Histoire (et Memoires) de l'Academie Royale des Sciences (Paris) 1711 (1714); pt 2, 151-6.

13 Pettigrew JB. On the arrangement of the muscular fibres in the ventricles of the vertebrate heart, with physiological remarks. Philos Trans 1865; 154: 445-500.
14 Lev M, Simkins CS. Architecture of the human ventricular myocardium. Lab Invest 1956; 5: 396-409.

15 Grant RP. Notes on the muscular architecture of the left ventricle. Circulation 1965; 32: 301-8.

16 Greenbaum RA, Ho SY, Gibson DG, Becker AE, Anderson RH. Left ventricular fibre architecture in man. Br Heart $\mathcal{f} 1981$; 45: 248-63.

17 Armour JA, Randall WC. Electrical and mechanical activity of papillary muscle. Am $\mathcal{F}$ Physiol 1970; 218: 1710-7.

18 Cronin R, Armour JA, Randall WC. Function of the in-situ papillary muscle in the canine left ventricle. Circ Res 1969; 25: 67-75.

Requests for reprints to Dr D G Gibson, Cardiac Department, Brompton Hospital, Fulham Road, London SW3 6HP. 